\title{
Removal of Soil Microbes Alters Interspecific Competitiveness of Epichlö̈ Endophyte-Infected over Endophyte-Free Leymus chinensis
}

\author{
Hui Liu ${ }^{1,2}$, Jing Chen ${ }^{1}$, Tianzi Qin ${ }^{1}$, Xinjian Shi ${ }^{1}$, Yubao Gao ${ }^{1}$ and Anzhi Ren ${ }^{1, *}$ \\ 1 College of Life Sciences, Nankai University, Tianjin 300071, China; liuhui@mail.nankai.edu.cn (H.L.); \\ chenjing@mail.nankai.edu.cn (J.C.); Tianzi@mail.nankai.edu.cn (T.Q.); xinjian@mail.nankai.edu.cn (X.S.); \\ ybgao@mail.nankai.edu.cn (Y.G.) \\ 2 College of Life Sciences, Dezhou University, Dezhou 253023, China \\ * Correspondence: renanzhi@nankai.edu.cn
}

Received: 30 December 2019; Accepted: 5 February 2020; Published: 6 February 2020

\begin{abstract}
Epichloë endophytes may not only affect the growth and resistances of host grasses, but may also affect soil environment including soil microbes. Can Epichloë endophyte-mediated modification of soil microbes affect the competitive ability of host grasses? In this study, we tested whether Epichloë endophytes and soil microbes alter intraspecific competition between Epichloë endophyte-colonized (EI) and endophyte-free (EF) Leymus chinensis and interspecific competition between L. chinensis and Stipa krylovii. The results demonstrated that Epichloë endophyte colonization significantly enhanced the intraspecific competitive ability of L. chinensis and that this beneficial effect was not affected by soil microbes. Under interspecific competition, however, significant interactions between Epichloë endophytes and soil microbes were observed. The effect of Epichloë endophytes on interspecific competitiveness of the host changed from positive to neutral with soil microbe removal. Here higher mycorrhizal colonization rates probably contributed to interspecific competitive advantages of EI over EF L. chinensis. Our result suggests that Epichloë endophytes can influence the competitive ability of the host through plant soil feedbacks from the currently competing plant species.
\end{abstract}

Keywords: Leymus chinensis; Epichloë endophyte; soil microbe; intraspecific competition; interspecific competition; Stipa krylovii

\section{Introduction}

Epichloë endophytes are a group of fungi characterized by their ability to infect the aerial tissues of several cool-season grasses without causing obvious disease [1]. Symbioses between grasses and Epichloë endophytes occur in both natural and agricultural grassland communities and are generally considered to be mutualistic [2-4]. The host plant provides food, shelter and a mode of reproduction for the fungus, while the fungus can increase host growth, reproduction, and resistance and tolerance to abiotic and biotic stress, such as drought [5-7], low nutrients [8-10], herbivory [3,11,12] and pathogen attack $[13,14]$.

Given the occurrence of Epichloë endophyte-improved plant fitness, Epichloë endophytes are assumed to enhance the intra- and interspecific competition ability of host plants [15-18]. In terms of intraspecific competition, greater shoot and/or root growth in Festuca arundinacea [19,20], Festuca pratensis [21], and Bromus benekenii [22] have been reported in association with the presence of Epichloë endophytes. With respect to interspecific competition, the greater competitive ability of plants harbouring Epichloë endophytes has been documented in F. pratensis [23,24], Poa alsodes [25], Festuca rubra [16] and Achnatherum sibiricum [18]. However, several studies have also reported conflicting results showing neutral to negative effects of endophytes on the competitive ability of the host [26-29]. 
Epichloë endophytes may not only affect the growth and resistances of host grasses, but may also affect soil microbes, such as nitrogen-fixing bacteria, phosphorus-solubilizing rhizospheric fungi, arbuscular mycorrhizal fungi (AMF) and other microbial communities [30-33]. Can Epichloë endophyte-mediated modification of soil microbes affect the competitive ability of host grasses indirectly? Limited studies focused on AMF. Omacini et al. [15] found that Epichloë endophyte colonization reduced AMF colonization of endophyte-infected (EI) Lolium multiflorum, while increased AMF colonization of neighbouring endophyte-free (EF) ryegrass. As AMF was neutral to both EI and EF plants, the modified colonization did not change the completive advantage of EI over EF plants. In a recent study, we found that Epichloë endophyte colonization significantly inhibited AMF colonization of the host grass Achnatherum sibiricum, and the effects of AMF on host competition were variable and depended on the identity of the AMF species [18]. As AMF diversity is high in natural grasslands, and Epichloë endophyte colonization can affect AMF as well as other microbes [32-34], we hypothesized that Epichloë endophyte colonization could not only affect the competitive ability of the host directly by changing its growth and resistance, but also indirectly by changing soil microbes.

Leymus chinensis and Stipa krylovii are two dominant species of the Inner Mongolia steppe. In the present study, we investigated the effects of Epichloë endophytes and soil microbes on the intraspecific competitive interactions between EI and EF L. chinensis and interspecific competitive interactions between L. chinensis and S. krylovii. Specifically, we focused on two primary questions: (1) Does Epichloë endophyte colonization affect the growth and intra- and interspecific competitive ability of L. chinensis? (2) Is the effect of Epichloë endophyte colonization on the growth and competitive ability of L. chinensis influenced by soil microbes?

\section{Materials and Methods}

\subsection{Plant and Fungal Material}

L. chinensis, a rhizomatous perennial grass, was originally sampled from their natural populations at Abaga Banner in Inner Mongolia $\left(43.90^{\circ} \mathrm{N}, 115.34^{\circ} \mathrm{E}\right)$. It can be colonized by the leaf endophyte Epichloë bromicola, and the infection rate was about 63\% [35]. In this area, L. chinensis seldom produces seeds, and stromata have not ever been observed, thus the endophyte is highly likely transmitted via vegetative propagation. EI and EF plants used in this experiment were originally collected from their natural population in summer in 2015, multiplied and selected for uniformity in 2016 and 2017. During this period, we clipped the plants repeatedly and kept them growing vegetatively aiming to avoid possible horizontal transmission of Epichloë endophyte, but only vertical transmission between different tillers. The Epichloë endophyte status of each L. chinensis plant was not only checked microscopically by examining the leaf sheaths for the presence of fungal hyphae after staining with lactophenol aniline blue [36] (Figure 1A) but also isolated (Figure 1B) and identified before conducting experiments to confirm endophyte status.

S. krylovii, a perennial bunchgrass, cannot be infected by Epichloë endophyte [37]. S. krylovii seeds were sampled from their natural populations at Abaga Banner in Inner Mongolia. After nine months of growth in the greenhouse at Nankai University, the plants that were almost the same size as L. chinensis were selected.

Soil was collected from the natural grassland hosting the two plant species at Abaga Banner in Inner Mongolia. We sieved the soil samples to remove roots and then pooled them for the experiment. Sterilized soils (which were autoclaved for $90 \mathrm{~min}$ at $121^{\circ} \mathrm{C}$ ) served as a microbe-free (MF) treatment. Non-sterilized soils were used as microbe-inclusive (MI) treatment. 


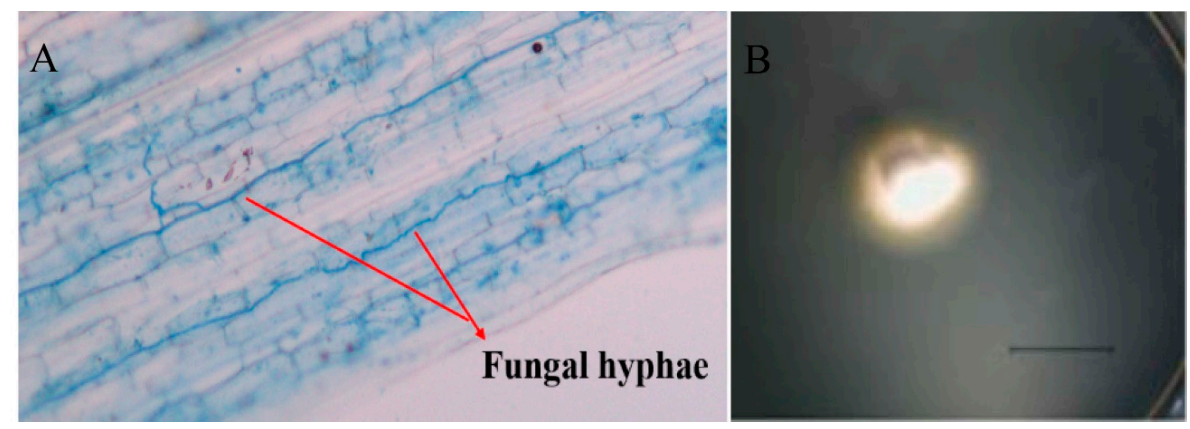

Figure 1. Hyphae in leaf sheath (A) (Shot under $4 \times$ microscope) and colony (B) of Epichloë bromicola isolated from Leymus chinensis. Picture of colony was taken after growing on PDA for 10 days (scale bars $=10 \mathrm{~mm}$ ).

\subsection{Experimental Design}

The experiment had a randomized block design with three factors. One factor, Epichloë endophyte colonization status of L. chinensis, contained two treatments: EI and EF L. chinensis. The second factor, soil microbe status, contained two treatments: MI and MF. These two factors were the same for both intra- and interspecific competition. The difference in the test of the two competition types were the third factor, plant mixture type: monoculture and mixture. The test of intraspecific competition included three groups: monoculture of EI L. chinensis (EI), monoculture of EF L. chinensis (EF) and mixture of EI and EF L. chinensis. In contrast, the test for interspecific competition involved five groups: EI, EF, monoculture of S. krylovii (S), mixture of EI L. chinensis and S. krylovii (EIS) and mixture of EF L. chinensis and S. krylovii (EFS) (Table 1)

Table 1. The experimental design schematic diagram.

\begin{tabular}{ccccccccc}
\hline & \multicolumn{2}{c}{ Intraspecific Competition } & \multicolumn{3}{c}{ Interspecific Competition } \\
\hline \multicolumn{2}{c}{ Monoculture } & Mixture & \multicolumn{2}{c}{ Monoculture } & \multicolumn{2}{c}{ Mixture } \\
\hline MI & EI & EF & EI and EF & EI & EF & S & EIS & EFS \\
MF & EI & EF & EI and EF & EI & EF & S & EIS & EFS \\
\hline
\end{tabular}

EI, Epichloë endophyte-colonized L. chinensis; EF, endophyte-free L. chinensis; EIS, S. krylovii grown with EI L. chinensis; EFS, S. krylovii grown with EF L. chinensis; MI, soil microbe inclusive; MF, soil microbe free.

A de Wit-type replacement series [38] with equal plant densities was used to assess the intraspecific competitive interaction between EI and EF L. chinensis and the interspecific competitive interaction between L. chinensis and S. krylovii. Six plant individuals per plant species for the monocultures and three + three individuals of each plant species for the mixtures were transplanted into each plastic pot (22-cm diameter and $17-\mathrm{cm}$ depth) containing $1.5 \mathrm{~kg}$ sterilized or non-sterilized soil, resulting in 12 combinations. Each combination was replicated five times, yielding a total of 60 pots. The experiment lasted 4 months, from 12 April 2018 to 12 August 2018, and was conducted in the campus experimental field at Nankai University, Tianjin, China. During the experiment, all pots were watered two or three times a week, and nutrients were supplied by the addition of Hoagland nutrient solution once per week to ensure the normal growth of plants.

\subsection{Biomass and Relative Yield (RY)}

At harvest, the shoots of each species were cut at the soil level, dried at $80^{\circ} \mathrm{C}$ for $24 \mathrm{~h}$, and then weighed. Roots were collected by gentle washing, separated according to species and divided into two groups. One group was dried at $80^{\circ} \mathrm{C}$ for $24 \mathrm{~h}$ and then weighed; the other group was kept at $-20^{\circ} \mathrm{C}$ for the determination of the AMF colonization rate. Relative yield (RY) was calculated as the ratio of the weight of the species in the mixture to the weight of the species in monoculture. 


\subsection{AMF Colonization Rate}

Colonization of the roots by AMF was microscopically assessed. A subsample (ca. $2 \mathrm{~g}$ ) of roots was cleared with $10 \%(w / v) \mathrm{KOH}$ before being stained using $0.05 \%$ trypan blue in lactic acid $(v / v)$ using a modified version of the procedure described in Phillips and Hayman [39]. Mycorrhizal colonization was determined by examining $15-251-\mathrm{cm}$ root segments at $200 \times$ magnification. The AMF colonization rate was recorded using the cross-hair eyepiece method [40], with a minimum of 200 intersections per replicate.

\subsection{Competitiveness}

The intraspecific competitive ability of EI against EF L. chinensis or interspecific competitive ability of $L$. chinensis against $S$. krylovii in the mixture pots was assessed using the aggressivity index (AGR) and the relative interaction intensity index (RII), both of which were calculated using the total biomass of the plant species. The AGR of species $x$ relative to species y was measured according to McGilchrist and Trenbath [41]:

$$
\mathrm{AGR}_{\mathrm{xy}}=\mathrm{RY} \mathrm{x}_{\mathrm{x}}-\mathrm{RY}_{\mathrm{y}}=\left(\mathrm{DM}_{\mathrm{xy}} / \mathrm{DM}_{\mathrm{xx}}\right)\left(\mathrm{D}-\mathrm{M}_{\mathrm{yx}} / \mathrm{DM}_{\mathrm{yy}}\right)
$$

where RY is the relative yield of species $x$ or $y$, defined as the dry matter yield of a species grown in mixture $\left(\mathrm{DM}_{\mathrm{xy}}\right.$ or $\left.\mathrm{DM}_{\mathrm{yx}}\right)$ relative to the dry matter in the respective monoculture $\left(\mathrm{DM}_{\mathrm{xx}}\right.$ or $\left.\mathrm{DM}_{\mathrm{yy}}\right)$. If the $A_{G R_{x y}}$ value is zero, then $x$ and $y$ have the same competitive ability. Species $x$ had a higher competitive ability than species $y$ if the $A_{G R}$ value was greater than zero. A negative $A_{G} R_{x y}$ value indicated the opposite.

The RII allows for simple comparisons of interaction strength across species and treatments [42]. The RII equation is as follows:

$$
\mathrm{RII}=\left(\mathrm{DM}_{\mathrm{xy}}-\mathrm{DM}_{\mathrm{xx}}\right) /\left(\mathrm{DM}_{\mathrm{xy}}+\mathrm{DM}_{\mathrm{xx}}\right)
$$

The RII is a measure of the strength of interactions between species and is centred on zero, with negative interactions (competition) indicated by values between 0 and -1 and positive interactions (facilitation) indicated by values between 0 and +1 .

\subsection{Statistical Analyses}

We performed all statistical analyses in the SPSS software (version 20.0, SPSS, Chicago, IL, USA). A two-way ANOVA was conducted to determine the effects of Epichloë endophyte colonization (E) and soil microbes (M) on the relative yield, AGR of L. chinensis and RII of both L. chinensis and S. krylovii and to analyse the effects of $\mathrm{E}$ and plant mixture type (C) on the mycorrhizal colonization rate of L. chinensis and to examine the effects of $\mathrm{M}$ and $\mathrm{C}$ on the relative yield of S. krylovii. We compared the competitiveness of EI relative to EF L. chinensis in intraspecific competition and mycorrhizal colonization rate among S, EIS and EFS in interspecific competition, so we only used one-way ANOVA examining the effect of $M$ on the AGR of L. chinensis and determining the effect of $C$ on the mycorrhizal colonization rate of S. krylovii.

\section{Results}

\subsection{Plant Growth Performance}

Growth of L. chinensis, in terms of RY was significantly increased by Epichloë endophyte colonization under both intra- and interspecific competition, but the extent of this effect was higher for intraspecific competition ( $26 \%$ versus $18 \%$, respectively) (Table 2, Figure 2A,C). Microbe removal significantly reduced the RY of L. chinensis under inter- but not intraspecific competition (Table 2, Figure 2B,D). There was no significant interaction between Epichloë endophytes and soil microbes on the RY of $L$. chinensis under either intra- or interspecific competition (Table 2). 
Table 2. Analyses of variance (ANOVA) for plant relative yield, mycorrhizal colonization rate, relative interaction intensity index (RII) and aggressivity index (AGR) of Leymus chinensis and Stipa krylovii.

\begin{tabular}{|c|c|c|c|c|c|c|c|c|c|c|c|c|c|c|c|c|}
\hline & \multicolumn{4}{|c|}{ Relative Yield } & \multicolumn{4}{|c|}{ Mycorrhizal Colonization Rate } & \multicolumn{4}{|c|}{ RII } & \multicolumn{4}{|c|}{ AGR } \\
\hline & \multicolumn{2}{|c|}{ Intra } & \multicolumn{2}{|c|}{ Inter } & \multicolumn{2}{|c|}{ Intra } & \multicolumn{2}{|c|}{ Inter } & \multicolumn{2}{|c|}{ Intra } & \multicolumn{2}{|c|}{ Inter } & \multicolumn{2}{|c|}{ Intra } & \multicolumn{2}{|c|}{ Inter } \\
\hline & $F$ & $P$ & $F$ & $P$ & $F$ & $P$ & $F$ & $P$ & $F$ & $P$ & $F$ & $P$ & $F$ & $P$ & $F$ & $P$ \\
\hline \multicolumn{17}{|l|}{ Leymus chinensis } \\
\hline $\begin{array}{c}\text { Epichloë } \\
\text { endophyte (E) }\end{array}$ & 16.573 & 0.004 & 6.287 & 0.037 & 12.945 & 0.007 & 33.228 & $<0.001$ & 18.441 & 0.003 & 5.672 & 0.044 & & & 12.097 & 0.008 \\
\hline Mycorrhiza (M) & 1.362 & 0.277 & 9.583 & 0.015 & & & & & 1.971 & 0.198 & 9.557 & 0.015 & 1.417 & 0.300 & 12.847 & 0.007 \\
\hline Competition (C) & & & & & 0.226 & 0.647 & 0.941 & 0.360 & & & & & & & & \\
\hline $\mathrm{E} \times \mathrm{M}$ & 1.769 & 0.220 & 2.915 & 0.126 & & & & & 2.242 & 0.173 & 2.416 & 0.159 & & & 10.713 & 0.011 \\
\hline $\mathrm{E} \times \mathrm{C}$ & & & & & 0.115 & 0.743 & 9.150 & 0.016 & & & & & & & & \\
\hline \multicolumn{17}{|l|}{$\mathrm{M} \times \mathrm{C}$} \\
\hline \multicolumn{17}{|l|}{$\mathrm{E} \times \mathrm{M} \times \mathrm{C}$} \\
\hline \multicolumn{17}{|l|}{ Stipa krylovii } \\
\hline $\begin{array}{c}\text { Epichloë } \\
\text { endophyte (E) }\end{array}$ & & & & & & & & & & & 7.873 & 0.023 & & & & \\
\hline Mycorrhiza (M) & & 2.243 & 0.173 & & & & & & & & 3.102 & 0.116 & & & & \\
\hline Competition (C) & & 6.605 & 0.033 & & & & 11.634 & 0.009 & & & & & & & & \\
\hline $\mathrm{E} \times \mathrm{M}$ & & & & & & & & & & & 16.626 & 0.004 & & & & \\
\hline $\mathrm{M} \times \mathrm{C}$ & & 15.096 & 0.005 & & & & & & & & & & & & & \\
\hline
\end{tabular}



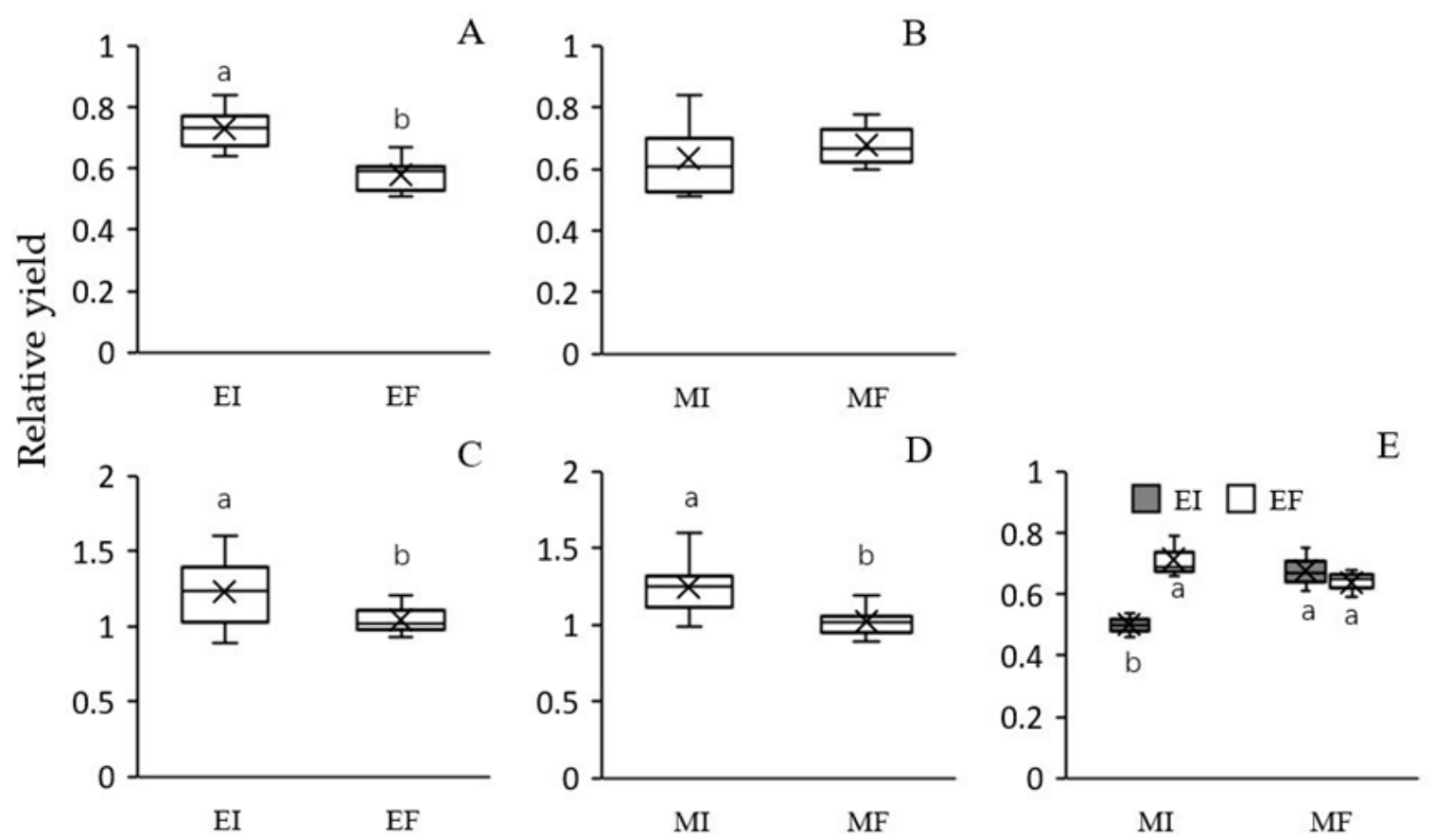

Figure 2. Effects of Epichloë endophyte colonization and soil microbes on the relative yield of Leymus chinensis both in intraspecific (A) and (B) and interspecific (C) and (D) competition and effect of the interaction between soil microbes and plant mixture type on the relative yield of Stipa krylovii (E). Values are means \pm SE $(n=5)$. The different letters above bars denote means that are significantly different among treatments $(p<0.05)$. EI, Epichloë endophyte-colonized L. chinensis; EF, endophyte-free L. chinensis; EIS, S. krylovii grown with EI L. chinensis; EFS, S. krylovii grown with EF L.chinensis; MI, soil microbe inclusive; MF, soil microbe free. Symbol ' $x$ ', horizontal line in the box, top and bottom of box edges and bars indicate the average value, median, $25 \%$ and $75 \%$ quartiles, and $5 \%$ and $95 \%$ quantiles, respectively.

The RY of S. krylovii was significantly affected by the interaction between soil microbes and plant mixture types (Table 2). In addition, there was no significant effect of Epichloë endophytes in L. chinensis on the RY of S. krylovii in the MF treatment, but Epichloë endophyte presence significantly suppressed the RY of S. krylovii in the MI treatment (Figure 2E). Thus, S. krylovii showed a higher RY when grown with EF than EI L. chinensis in the MI treatment (Figure 2E).

\subsection{AMF Colonization Rate}

Epichloë endophyte colonization significantly increased the mycorrhizal colonization rate of $L$. chinensis under both intra- and interspecific competition, and this increase was more pronounced under interspecific competition (Table 2, Figure 3A). The mycorrhizal colonization rate of S. krylovii was similar in mixtures with $\mathrm{EF}$ L. chinensis to those in monocultures, which suggests that $L$. chinensis did not affect the mycorrhizal colonization rate of its neighbouring plants. However, the mycorrhizal colonization rate of S. krylovii was higher when grown with EF L. chinensis plants than when grown with EI plants, which suggests that Epichloë endophyte colonization could inhibit the mycorrhizal colonization rate of neighbouring plants (Table 2, Figure 3B). 

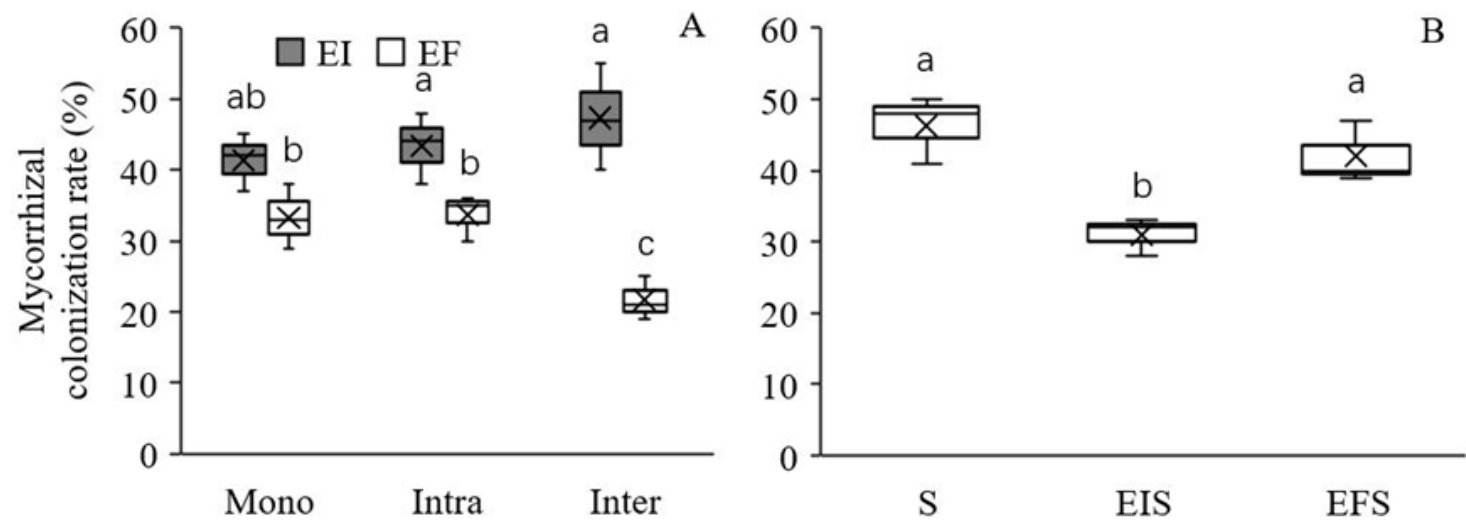

Figure 3. Effect of Epichloë endophyte colonization on the mycorrhizal colonization rate of Leymus chinensis (A) and Stipa krylovii (B). The different letters above bars denote means that are significantly different among treatments $(p<0.05)$. Mono, monoculture; Intra, intraspecific competition; Inter, interspecific competition; S, the monoculture of S. krylovii; EIS, S. krylovii grown with EI L. chinensis; EFS, S. krylovii grown with EF L. chinensis. Symbol ' $X$ ', horizontal line in the box, top and bottom of box edges and bars indicate the average value, median, $25 \%$ and $75 \%$ quartiles, and $5 \%$ and $95 \%$ quantiles, respectively.

\subsection{Competitiveness}

The AGR was used to measure the competitive ability of EI L. chinensis relative to EF L. chinensis. Under intraspecific competition, the AGR of L. chinensis was positive in the MI treatment, indicating a greater competitive ability of EI L. chinensis relative to that of EF L. chinensis (Figure $4 \mathrm{~A}$ ), but no significant main effect of soil microbes was observed (Table 2). Under interspecific competition, the AGR was significantly affected by Epichloë endophyte colonization, soil microbes and their interaction (Table 2). L. chinensis had a greater competitive ability than S. krylovii (AGR > 0). In addition, there was no significant effect of Epichloë endophytes on the interspecific competitive ability of L. chinensis in the MF treatment, but a higher competitive ability of EI L. chinensis compared to EF L. chinensis was observed in the MI treatment (Figure 4B).
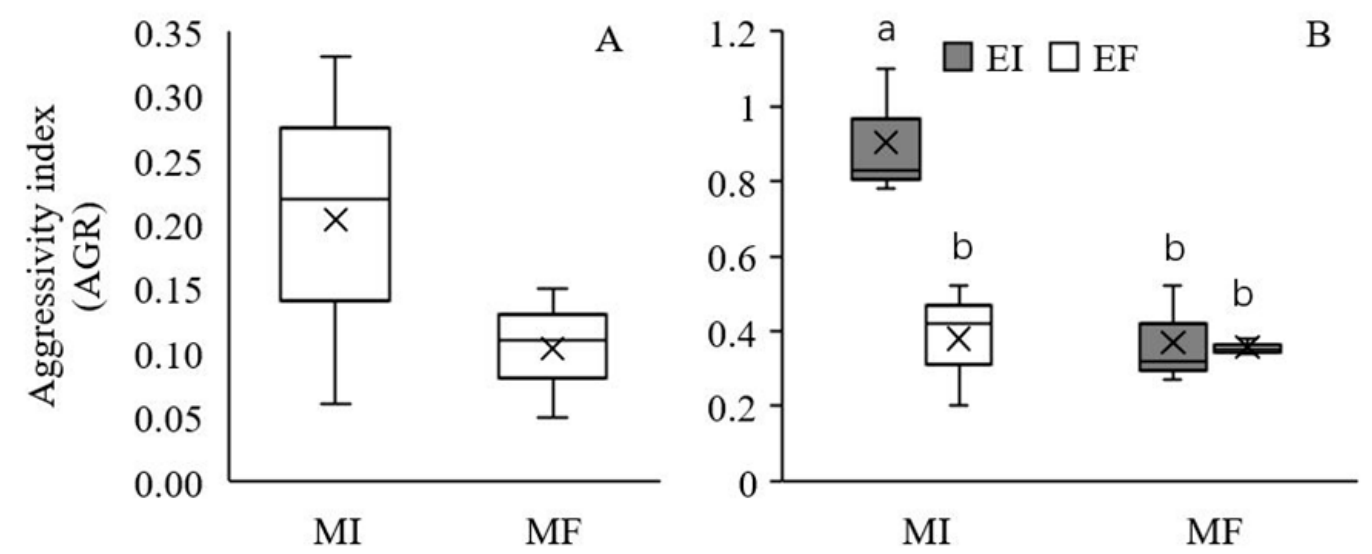

Figure 4. Effect of soil microbes on the aggressivity index (AGR) of Leymus chinensis in intraspecific competition (A) and effect of the interaction between Epichloë endophyte colonization and soil microbes on the AGR of L. chinensis in interspecific competition (B). The different letters above bars denote means that are significantly different among treatments $(p<0.05)$. EI, Epichloë endophyte-colonized $L$. chinensis; EF, endophyte-free L. chinensis; MI, soil microbe inclusive; MF, soil microbe free. Symbol ' $\times$ ', horizontal line in the box, top and bottom of box edges and bars indicate the average value, median, $25 \%$ and $75 \%$ quartiles, and $5 \%$ and $95 \%$ quantiles, respectively. 
The RII provides a simple comparison of interaction strength across species and treatments. Under intraspecific competition, the RII values of both EI and EF L. chinensis were negative in both the MI and MF treatments, and only the RII of EI L. chinensis was less negative compared to that of EF $L$. chinensis (Table 2, Figure 5A,B). The results indicate that EI and EF L. chinensis suppressed each other, but the magnitude of the negative effect of EI on EF L. chinensis was larger. The presence of soil microbes did not have a significant effect on the RII of L. chinensis (Table 2, Figure 5B). In terms of the response of $L$. chinensis to competition with $S$. krylovii, the presence of $S$. krylovii facilitated the growth of EI L. chinensis (RII > 0) but had no influence on EF L. chinensis, and a significant main effect of Epichloë endophytes was observed (Table 2, Figure 5C). In addition, the presence of soil microbes significantly enhanced the promoting effect of S. krylovii on L. chinensis under interspecific competition (Table 2, Figure 5D). However, no significant interactive effect between Epichloë endophytes and soil microbes was observed (Table 2). The RII of S. krylovii was significantly affected by Epichloë endophyte colonization, soil microbes and their interaction (Table 2). Furthermore, L. chinensis had a negative effect on S. krylovii (RII < 0). Epichloë endophyte colonization had no significant effect on the RII in the MF treatment, but a stronger negative effect of EI L. chinensis on S. krylovii was observed in the MI treatment (Figure 5E).

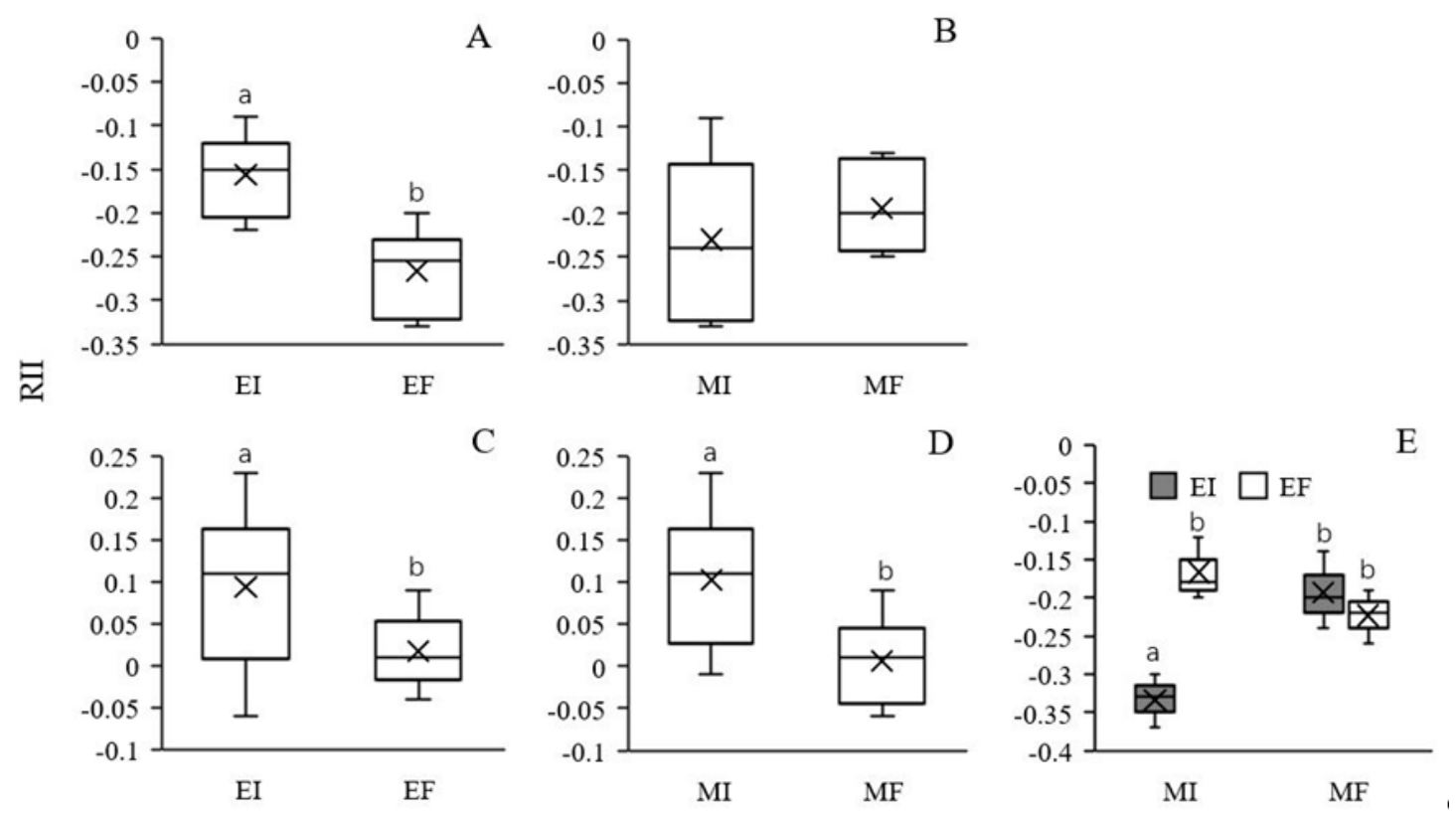

Figure 5. Effects of Epichloë endophyte colonization and soil microbes on the relative interaction intensity index (RII) between EI and EF Leymus chinensis (A) and (B) in intraspecific competition and between L. chinensis and Stipa krylovii for L. chinensis in interspecific competition (C) and (D) and effect of the interaction between Epichloë endophyte colonization and soil microbes on the RII between L. chinensis and S. krylovii for S. krylovii in interspecific competition (E). The different letters above bars denote means that are significantly different among treatments $(p<0.05)$. EI, Epichloë endophyte-colonized $L$. chinensis; EF, endophyte-free L. chinensis; MI, soil microbe inclusive; MF, soil microbe free. Symbol ' $\times$ ', horizontal line in the box, top and bottom of box edges and bars indicate the average value, median, $25 \%$ and $75 \%$ quartiles, and $5 \%$ and $95 \%$ quantiles, respectively.

\section{Discussion}

With respect to the effects of Epichloë endophyte colonization on plant competitiveness, published studies on the intraspecific or interspecific competitive ability of hosts have focused on different grass-endophyte symbionts. Epichloë endophytes can enhance the competitive ability of host plants either by promoting self-growth or by inhibiting the growth of companion plants. For example, Brem and Leuchtman [22] conducted an intraspecific competition experiment and found that Epichloë 
endophytes enhanced the competitive ability of Br. benekenii by increasing its aboveground dry matter yield. In relation to the interspecific competition experiment, Craig et al. [25] showed that Epichloë endophytes increased the biomass of host P. alsodes. Saikkonen et al. [24] also demonstrated that Epichloë endophytes conferred a competitive advantage to the host, F. pratensis, thereby reducing weed invasions. However, Vázquez-de-Aldana et al. [16] evaluated the effect of Epichloë endophyte colonization on the competitive ability of F. rubra against five other grassland species in binary mixtures and found that EI plants had better competitive ability than EF plants, as indicated by the lower RY of companion plants when growing in mixture with EI plants. Certainly, neutral $[28,29]$ and negative $[26,27]$ effects of symbiosis when infected plants grow in competition with other species have also been reported. Are the effects of Epichloë endophyte colonization on intraspecific and interspecific competition similar for a single grass-endophyte symbiont? The only study that has addressed this question was conducted by Marks et al. [20], who found that Epichloë endophyte colonization enhanced both the intra- and interspecific competitive ability of tall fescue but decreased the intra- and interspecific competitive ability of perennial ryegrass. In our study, we found that Epichloë endophyte colonization enhanced both the intra- and interspecific competitive ability of L. chinensis, only the beneficial effects of Epichloë endophyte colonization on the interspecific competitiveness of the host were affected by soil microbes.

In natural systems, plants often experience direct competition with neighbouring plants and simultaneous complex interactions with soil biota [43]. Epichloë endophyte colonization can shape communities of soil biota [44-48] and influence subsequent plant growth and survival [49-52]. Can simultaneous occurrence of foliar Epichloë endophytes and soil microbes affect the competitivity of the host grasses? Up to now, only the effects of simultaneous occurrence of foliar Epichloë endophytes and AMF were reported and the results were varied. Omacini et al. [15], in binary mixtures of EI and EF Lolium multiflorum, found that the competitive ability of plants was increased by the presence of Epichloë endophytes, while AMF did not affect host performance in the presence or absence of Epichlö endophytes. Vignale et al. [53], in binary mixtures of EI and EF Bromus auleticus, showed that neither Epichloë endophytes nor AMF affected the intraspecific competitive ability of the plants. In our previor study [18], we found that Epichloë endophyte colonization significantly enhanced the interspecific competitive ability of A. sibiricum, but there was no interaction between AMF and Epichloë endophytes. In the present study, we found that the effect of Epichloë endophyte colonization on the intra- and interspecific competitive ability of L. chinensis was differentially mediated by soil microbes. Soil microbe presence did not affect the intraspecific competitive ability of EI relative to EF L. chinensis. However, with respect to interspecific competition, we did find significant interactions between Epichloë endophytes and soil microbes on the competitiveness of L. chinensis. The effect of Epichloë endophytes on interspecific competitiveness of the host changed from positive to neutral with soil microbe removal.

Why did soil microbes not affect the intraspecific competitive ability but change the interspecific competitive ability of EI over EF L. chinensis? In the present study, we investigated AMF colonization rates of L. chinensis and S. krylovii, and found that AMF colonization rates of EF L. chinensis was significantly lower in interspecific competitive studies than those in monoculture and intraspecific competitive studies, while the AMF colonization rates of EI L. chinensis did not change significantly. The advantage of EI over EF L. chinensis in the mycorrhizal colonization was more evident in interspecific than intraspecific studies. Higher mycorrhizal colonization rates probably contributed to higher interspecific competitive advantages of EI over EF L. chinensis.

Plants can shape communities of soil biota and alter soil structure and chemistry in ways that influence subsequent plant growth and survival. The effects of Epichloë endophyte colonization on these plant-soil feedbacks (PSFs) have been found both in host grasses as well as in neighbouring plants in the community. Matthew and Clay [50] found that EI Festuca had reduced growth in soil that previously supported EI Festuca, but was unaffected by soil that once supported EF Festuca. Rudgers and Orr [48] reported that soil conditioning by EI tall fescue reduced the biomass of three native tree species via altered soil microbes. In the present study, we found that the effect of Epichloë endophytes on interspecific competitiveness changed from positive to neutral with microbe removal. The result 
suggests that the soil feedback effect of the EI plants can build up quickly during competition. Thus, Epichloë endophytes can influence the competitive ability of the host through plant-soil feedbacks from the currently competing plant species.

Author Contributions: Conceptualization, A.R. and H.L.; methodology, A.R. and H.L.; software, H.L. and T.Q.; validation, H.L. and X.S.; formal analysis, A.R. and H.L.; investigation, H.L. and J.C.; resources, A.R.; data curation, H.L., J.C. and T.Q.; writing-original draft preparation, H.L. and A.R.; writing-review and editing, H.L., Y.G. and A.R.; visualization, X.S. and Y.G.; supervision, H.L. and A.R.; project administration, A.R.; funding acquisition, A.R. All authors have read and agreed to the published version of the manuscript.

Funding: This work was supported by the National Key Research and Development Program (2016YFC0500702), National Natural Science Foundation of China (31570433 and 31971425) and Dezhou University Science Research Foundation (2019xjrc317).

Conflicts of Interest: The authors declare no conflict of interest.

\section{References}

1. Arnold, A.E.; Maynard, Z.; Gilbert, G.S.; Coley, P.D.; Kursar, T.A. Are tropical fungal endophytes hyperdiverse? Ecol. Lett. 2000, 3, 267-274. [CrossRef]

2. Clay, K. Fungal endophytes of grasses. Annu. Rev. Ecol. Syst. 1990, 21, 275-297. [CrossRef]

3. Clay, K.; Schardl, C. Evolutionary origins and ecological consequences of endophyte symbiosis with grasses. Am. Nat. 2002, 160, S99-S127. [CrossRef] [PubMed]

4. Saikkonen, K.; Wali, P.; Helander, M.; Faeth, S.H. Evolution of endophyte-plant symbioses. Trends Plant Sci. 2004, 9, 275-280. [CrossRef] [PubMed]

5. Bacon, C.W.; White, J.F. Physiology and Drought Tolerance of Endophyte-Infected Grasses; CRC Press: Boca Raton, FL, USA, 1994.

6. Kannadan, S.; Rudgers, J.A. Endophyte symbiosis benefits a rare grass under low water availability. Funct. Ecol. 2008, 22, 706-713. [CrossRef]

7. Liu, H.; Chen, W.; Wu, M.; Wu, R.H.; Zhou, Y.; Gao, Y.B.; Ren, A.Z. Arbuscular mycorrhizal fungusinoculation reduces the drought-resistance advantage of endophyte-infected versus endophyte-free Leymus chinensis. Mycorrhiza 2017, 27, 791-799. [CrossRef]

8. Malinowski, D.P.; Belesky, D.P. Neotyphodium coenophialum endophyte infection affects the ability of tall fescue to use sparingly available phosphorus. J. Plant Nutr. 1999, 22, 835-853. [CrossRef]

9. Malinowski, D.P.; Alloush, G.A.; Belesky, D.P. Leaf endophyte Neotyphodium coenophialum modifies mineral uptake in tall fescue. Plant Soil 2000, 227, 115-126. [CrossRef]

10. Rahman, M.H.; Saiga, S. Endophytic fungi (Neotyphodium coenophialum) affect the growth and mineral uptake, transport and efficiency ratios in tall fescue (Festuca arundinacea). Plant Soil 2005, 272, 163-171. [CrossRef]

11. Clay, K. Fungal endophytes of grasses: A defensive mutualism between plants and fungi. Ecology 1988, 69, 10-16. [CrossRef]

12. Breen, J.P. Acremonium endophyte interactions with enhanced plant resistance to insects. Annu. Rev. Entomol. 1994, 39, 401-423. [CrossRef]

13. Mahmood, T.; Gergerich, R.C.; Milus, E.A.; West, C.P.; Darcy, C.J. Barley yellow dwarf viruses in wheat, endophyte-infected and endophyte-free tall fescue, and other hosts in Arkansas. Plant Dis. 1993, 77, 225-228. [CrossRef]

14. Wang, X.Y.; Qin, J.H.; Chen, W.; Zhou, Y.; Ren, A.Z.; Gao, Y.B. Pathogen resistant advantage of endophyte-infected over endophyte-free Leymus chinensis is strengthened by pre-drought treatment. Eur. J. Plant Pathol. 2016, 144, 477-486. [CrossRef]

15. Omacini, M.; Eggers, T.; Bonkowski, M.; Gange, A.C.; Jones, T.H. Leaf endophytes affect mycorrhizal status and growth of coinfected and neighbouring plants. Funct. Ecol. 2006, 20, 226-232. [CrossRef]

16. Vázquez-de-Aldana, B.R.; Zabalgogeazcoa, I.; Garcia-Ciudad, A.; Garcia-Criado, B. An Epichloë endophyte affects the competitive ability of Festuca rubra against other grassland species. Plant Soil 2013, 362, 201-213. [CrossRef]

17. Wu, L.J.; Ren, A.Z.; Jing, Y.F.; Zhou, Y.; Wang, X.Y.; Qin, J.H.; Gao, Y.B. Endophytic benefit for a competitive host is neutralized by increasing ratios of infected plants. Acta Oecologica 2016, 70, 112-120. [CrossRef] 
18. Zhou, Y.; Li, X.; Gao, Y.; Liu, H.; Gao, Y.B.; van der Heijden, M.G.A.; Ren, A.Z. Plant endophytes and arbuscular mycorrhizal fungi alter plant competition. Funct. Ecol. 2018, 32, 1168-1179. [CrossRef]

19. Hill, N.S.; Belesky, D.P.; Stringer, W.C. Competitiveness of tall fescue as influenced by Acremomium coenophialum. Crop Sci. 1991, 31, 185-190. [CrossRef]

20. Marks, S.; Clay, K.; Cheplick, G.P. Effects of fungal endophytes on interspecific and intraspecific competition in the grasses Festuca arundinacea and Lolium perenne. J. Appl. Ecol. 1991, 28, 194-204. [CrossRef]

21. Malinowski, D.P.; Leuchtmann, A.; Schmidt, D.; Nösberger, J. Growth and water status in meadow fescue is affected by Neotyphodium and Phialophora species endophytes. Agron. J. 1997, 89, 673-678. [CrossRef]

22. Brem, D.; Leuchtmann, A. Intraspecific competition of endophyte infected vs uninfected plants of two woodland grass species. Oikos 2002, 96, 281-290. [CrossRef]

23. Takai, T.; Sanada, Y.; Yamada, T. Influence of the fungal endophyte Neotyphodium uncinatum on the persistency and competitive ability of meadow fescue (Festuca pratensis Huds.). Grassl. Sci. 2010, 56, 59-64. [CrossRef]

24. Saikkonen, K.; Ruokolainen, K.; Huitu, O.; Gundel, P.E.; Piltti, T.; Hamilton, C.E.; Helander, M. Fungal endophytes help prevent weed invasions. Agric. Ecosyst. Environ. 2013, 165, 1-5. [CrossRef]

25. Craig, S.; Kannadan, S.; Flory, S.L.; Seifert, E.K.; Whitney, K.D.; Rudgers, J.A. Potential for endophyte symbiosis to increase resistance of the native grass Poa alsodes to invasion by the nonnative grass Microstegium vimineum. Symbiosis 2011, 53, 17-28. [CrossRef]

26. Richmond, D.; Grewal, P.; Cardina, J. Competition between Lolium perenne and Digitaria sanguinalis: Ecological consequences for harbouring an endosymbiotic fungus. J. Veg. Sci. 2003, 14, 835-840. [CrossRef]

27. Faeth, S.H.; Helander, M.L.; Saikkonen, K.T. Asexual Neotyphodium endophytes in a native grass reduce competitive abilities. Ecol. Lett. 2004, 7, 304-313. [CrossRef]

28. Cheplick, G.P.; Harrichandra, A.P.; Liu, A.A. Competitive outcomes depend on host genotype, but not clavicipitaceous fungal endophytes, in Lolium perenne (Poaceae). Am. J. Bot. 2014, 101, 2068-2078. [CrossRef]

29. Dirihan, S.; Helander, M.L.; Saloniemi, I.; Gundel, P.E.; Saikkonen, K. Effects of systemic fungal endophytes on the performance of meadow fescue and tall fescue in mixtures with red clover. Grass Forage Sci. 2014, 70, 465-473. [CrossRef]

30. Larimer, A.L.; Bever, J.D.; Clay, K. Consequences of simultaneous interactions of fungal endophytes and arbuscular mycorrhizal fungi with a shared host grass. Oikos 2012, 121, 2090-2096. [CrossRef]

31. Arrieta, A.M.; Iannone, L.J.; Scervino, J.M.; Vignale, M.V.; Novas, M.V. A foliar endophyte increases the diversity of phosphorus solubilizing rhizospheric fungi and mycorrhizal colonization in the wild grass Bromus auleticus. Fungal Ecol. 2015, 17, 146-15432. [CrossRef]

32. García Parisi, P.A.; Lattanzi, F.A.; Grimoldi, A.A.; Omacini, M. Multi-symbiotic systems: Functional implications of the coexistence of grass-endophyte and legume-rhizobia symbioses. Oikos 2015, 124, 553-560. [CrossRef]

33. Bell-Dereske, L.; Takacs-Vesbach, C.; Kivlin, S.N.; Emery, S.M.; Rudgers, J.A. Leaf endophytic fungus interacts with precipitation to alter belowground microbial communities in primary successional dunes. FEMS Microbiol. Ecol. 2017, 93, 1-16. [CrossRef] [PubMed]

34. Zhou, Y.; Li, X.; Qin, J.H.; Liu, H.; Chen, W.; Niu, Y.; Ren, A.Z.; Gao, Y.B. Effects of simultaneous infections of endophytic fungi and arbuscular mycorrhizal fungi on the growth of their shared host grass Achnatherum sibiricum under varying $\mathrm{N}$ and P supply. Fungal Ecol. 2016, 20, 56-65. [CrossRef]

35. Zhu, M.J.; Ren, A.Z.; Wen, W.; Gao, Y.B. Diversity and taxonomy of endophytes from Leymus chinensis in the Inner Mongolia steppe of China. FEMS Microbiol. Lett. 2013, 340, 135-145. [CrossRef] [PubMed]

36. Latch, G.C.M.; Christensen, M.J.; Samuels, G.J. Five endophytes of Lolium and Festuca in New Zealand. Mycotaxon 1984, 167, 338-342.

37. Wei, Y.K.; Gao, Y.B.; Xu, H.; Su, D.; Zhang, X.; Wang, Y.H.; Lin, F.; Chen, L.; Nie, L.Y.; Ren, A.Z. Occurrence of endophytes in grasses native to northern China. Grass Forage Sci. 2006, 61, 422-429. [CrossRef]

38. de Wit, C.T. On competition. Versl. Landbouwkd. Onderz. 1960, 66, 1-82.

39. Phillips, J.M.; Hayman, D.S. Improved procedures for clearing roots and staining parasitic and vesicular arbuscular mycorrhizal fungi for rapid assessment of infection. Trans. Br. Mycol. Soc. 1970, 55, 158-161. [CrossRef]

40. McGonigle, T.P.; Miller, M.H.; Evans, D.G.; Fairchild, G.L.; Swan, J.A. A new method which gives an objective measure of colonization of roots by vesicular-arbuscular mycorrhizal fungi. New Phytol. 1990, 115, 495-501. [CrossRef] 
41. McGilchrist, C.A.; Trenbath, B.R. A revised analysis of plant competition experiments. Biometrics 1971, 27, 659-671. [CrossRef]

42. Aschehoug, E.T.; Metlen, K.L.; Callaway, R.M.; Newcombe, G. Fungal endophytes directly increase the competitive effects of an invasive forb. Ecology 2012, 93, 3-8. [CrossRef] [PubMed]

43. Lekberg, Y.; Bever, J.D.; Bunn, R.A.; Callaway, R.M.; Hart, M.M.; Kivlin, S.N.; Klironomos, J.; Larkin, B.G.; Maron, J.L.; Reinhart, K.O.; et al. Relative importance of competition and plant-soil feedback, their synergy, context dependency and implications for coexistence. Ecol. Lett. 2018, 21, 1268-1281. [CrossRef] [PubMed]

44. Franzluebbers, A.J. Short-term responses of soil C and N fractions to tall fescue endophyte infection. Plant Soil 2006, 282, 153-164. [CrossRef]

45. Jenkins, M.B.; Franzluebbers, A.J.; Humayoun, S.B. Assessing short-term responses of prokaryotic communities in bulk and rhizosphere soils to tall fescue endophyte infection. Plant Soil 2006, 289, 309-320. [CrossRef]

46. Buyer, J.S.; Zuberer, D.A.; Nichols, K.A.; Alan, J.; Franzluebbers, A.J. Soil microbial community function, structure, and glomalin in response to tall fescue endophyte infection. Plant Soil 2011, 339, 401-412. [CrossRef]

47. Casas, C.; Omacini, M.; Montecchia, M.S.; Correa, O.S. Soil microbial community responses to the fungal endophyte Neotyphodium in Italian ryegrass. Plant Soil 2011, 340, 347-355. [CrossRef]

48. Bowatte, S.; Barrett, B.; Luscombe, C.; Hume, D.E.; Luo, D.; Theobald, P.; Newton, P.C.D. Effect of grass species and fungal endophyte on soil nitrification potential. N. Z. J. Agric. Res. 2011, 54, 275-284. [CrossRef]

49. Rudgers, J.A.; Orr, S. Non-native grass alters growth of native tree species via leaf and soil microbes. J. Ecol. 2009, 97, 247-255. [CrossRef]

50. Matthews, J.W.; Clay, K. Influence of fungal endophyte infection on plant-soil feedback and community interactions. Ecology 2001, 82, 500-509.

51. Cripps, M.G.; Edwards, G.R.; Mckenzie, S.L. Grass species and their fungal symbionts affect subsequent forage growth. Basic Appl. Ecol. 2013, 14, 225-234. [CrossRef]

52. Garcia-Parisi, P.A.; Lattanzi, F.A.; Grimoldi, A.A.; Druille, M.; Omacini, M. Three symbionts involved in interspecific plant-soil feedback: Epichloid endophytes and mycorrhizal fungi affect the performance of rhizobia-legume symbiosis. Plant Soil 2017, 412, 151-162. [CrossRef]

53. Vignale, M.V.; Iannone, L.J.; Scervino, J.M.; Novas, M.V. Epichloë exudates promote in vitro and in vivo arbuscular mycorrhizal fungi development and plant growth. Plant Soil 2018, 422, 267-281. [CrossRef] 